\title{
Clinical and Pharmacokinetic Outcomes of Peak-Trough-Based Versus Trough-Based Vancomycin Therapeutic Drug Monitoring Approaches: A Pragmatic Randomized Controlled Trial
}

\author{
Fatima Khalifa Al-Sulaiti ${ }^{1,2}$. Ahmed Mohamed Nader ${ }^{3} \cdot$ Mohamed Omar Saad $^{4} \cdot$ Adila Shaukat $^{5}$. \\ Rakesh Parakadavathu ${ }^{6} \cdot$ Ahmed Elzubair $^{7} \cdot$ Daoud Al-Badriyeh $^{1} \cdot$ Hazem Elewa $^{1} \cdot$ Ahmed Awaisu $^{1}$ (1)
}

Published online: 27 March 2019

(c) The Author(s) 2019

\begin{abstract}
Background Vancomycin therapeutic drug monitoring (TDM) is based on achieving 24-h area under the concentration-time curve to minimum inhibitory concentration cure breakpoints ( $\mathrm{AUC}_{24} / \mathrm{MIC}$ ). Approaches to vancomycin TDM vary, with no head-to-head randomized controlled trial (RCT) comparisons to date.

Objectives We aimed to compare clinical and pharmacokinetic outcomes between peak-trough-based and trough-only-based vancomycin TDM approaches and to determine the relationship between vancomycin $\mathrm{AUC}_{24} / \mathrm{MIC}$ and cure rates.

Methods A multicentered pragmatic parallel-group RCT was conducted in Hamad Medical Corporation hospitals in Qatar. Adult non-dialysis patients initiated on vancomycin were randomized to peak-trough-based or trough-only-based vancomycin TDM. Primary endpoints included vancomycin $\mathrm{AUC}_{24} / \mathrm{MIC}$ ratio breakpoint for cure and clinical effectiveness (therapeutic cure vs therapeutic failure). Descriptive, inferential, and classification and regression tree (CART) statistical analyses were applied. NONMEM.v.7.3 was used to conduct population pharmacokinetic analyses and $\mathrm{AUC}_{24}$ calculations.

Results Sixty-five patients were enrolled [trough-only-based-TDM $(n=35)$ and peak-trough-based-TDM $(n=30)$ ]. Peaktrough-based TDM was significantly associated with higher therapeutic cure rates compared to trough-only-based TDM [76.7\% vs $48.6 \% ; p$ value $=0.02$ ]. No statistically significant differences were observed for all-cause mortality, neutropenia, or nephrotoxicity between the two groups. Compared to trough-only-based TDM, peak-trough-based TDM was associated with less vancomycin total daily doses by $12.05 \mathrm{mg} / \mathrm{kg} /$ day $(p$ value $=0.027)$. CART identified creatinine clearance $\left(\mathrm{CL}_{\mathrm{CR}}\right)$, $\mathrm{AUC}_{24} / \mathrm{MIC}$, and TDM approach as significant determinants of therapeutic outcomes. All patients $[n=19,100 \%]$ with $\mathrm{CL}_{\mathrm{CR}} \leq 7.85 \mathrm{~L} / \mathrm{h}, \mathrm{AUC}_{24} / \mathrm{MIC} \leq 1256$, who received peak-trough-based TDM achieved therapeutic cure. $\mathrm{AUC}_{24} / \mathrm{MIC}>565$ was identified to be correlated with cure in trough-only-based TDM recipients $[n=11,84.6 \%]$. No minimum $\mathrm{AUC}_{24} / \mathrm{MIC}$ breakpoint was detected by CART in the peak-trough-based group.

Conclusion Maintenance of target vancomycin exposures and implementation of peak-trough-based vancomycin TDM may improve vancomycin-associated cure rates. Larger scale RCTs are warranted to confirm these findings.
\end{abstract}

Ahmed Awaisu

aawaisu@qu.edu.qa

1 Clinical Pharmacy and Practice Section, College of Pharmacy, Qatar University, P.O. Box 2713, Doha, Qatar

2 Qatar National Research Fund, Qatar Foundation, Doha, Qatar

3 Clinical Pharmacology and Pharmacometrics, AbbVie, North Chicago, IL, USA
4 Clinical Pharmacy Department, Al-Wakrah Hospital, Hamad Medical Corporation, Doha, Qatar

5 Infectious Diseases Department, Al-Wakrah Hospital, Hamad Medical Corporation, Doha, Qatar

6 Infectious Diseases Department, Hamad General Hospital, Hamad Medical Corporation, Doha, Qatar

7 Clinical Pharmacy Department, Al-Khor Hospital, Hamad Medical Corporation, Al-Khor, Qatar 


\section{Key points}

Compared to trough-based vancomycin TDM, peaktrough-based vancomycin TDM was associated with a higher clinical success rate and less vancomycin dose requirements.

Maintaining $\mathrm{AUC}_{24} / \mathrm{MIC}$ between 565 and 1256 has been associated with cure.

\section{Introduction}

Therapeutic drug monitoring (TDM) of vancomycin is essential in ensuring the attainment of positive clinical outcomes and minimizing toxicity [1]. Vancomycin clinical pharmacokinetic parameters exhibit large inter-individual variability even with identical dosing regimens [2]. Traditionally, steady-state vancomycin peak $\left(C_{\text {max,ss }}\right)$ and trough $\left(C_{\text {trough,ss }}\right)$ concentrations were measured for vancomycin TDM. In 2009, a paradigm shift in clinical vancomycin dosing and monitoring practices emerged, following the release of a consensus guideline jointly by the American Society of Health-System Pharmacists (ASHP), the Society of Infectious Diseases Pharmacists, and the Infectious Disease Society of America (IDSA) [3]. Based on limited clinical data and animal studies, vancomycin was considered 'concentration-independent' and thus $C_{\text {max,ss }}$ monitoring was no longer recommended. Additionally, a 24-h area under the concentration-time curve $\left(\mathrm{AUC}_{24}\right)$ to minimum inhibitory concentration (MIC) ratio $\left(\mathrm{AUC}_{24} / \mathrm{MIC}\right)$ of $\geq 400$ was defined as the target surrogate to attain clinical effectiveness. These guidelines recommended $C_{\text {trough,ss }}$ monitoring as a surrogate for achieving $\mathrm{AUC}_{24} / \mathrm{MIC} \geq 400$ with a value of $15-20 \mathrm{mg} / \mathrm{L}$ as an acceptable therapeutic range.

Published evidence after 2009 called into question the recommended target ratio $\left(\mathrm{AUC}_{24} / \mathrm{MIC} \geq 400\right)$ [4], as different AUC/MIC ratios have been found to achieve clinical effectiveness [5-7]. This reported variability in AUC/ MIC breakpoints may be attributed to the genetic variability between methicillin-resistant Staphylococcus aureus (MRSA) strains across different geographical areas [8-18], the differences in MRSA site of infection, and the variability of the populations studied in terms of comorbidities and ethnicities [19]. Hence, the generalizability of the published literature remains limited to different disease states, geographical regions, and populations. Furthermore, recent studies questioned the use of $C_{\text {trough,ss }}$ as an indicator of $\mathrm{AUC}_{24} / \mathrm{MIC}$ optimal exposure, as discrepancies between optimal $\mathrm{AUC}_{24}$ exposures and the associated trough concentrations have been reported [2, 20-24]. The superior clinical utility of multiple-concentration-based vancomycin dosing approaches compared to trough-only guided dosing has been suggested [21-23]. One of those approaches is peak-trough-based pharmacokinetic dosing [20, 23, 25]. Collectively, these studies raised concerns regarding the optimal vancomycin $\mathrm{AUC}_{24} / \mathrm{MIC}$ breakpoint for cure, and the best vancomycin TDM approach that would result in the attainment of the optimal $\mathrm{AUC}_{24} / \mathrm{MIC}$ ratio associated with clinical effectiveness.

The use of vancomycin in the treatment of serious Grampositive infections has become very challenging in Asia, including the Middle East and North Africa (MENA) region $[16,26,27]$. A meta-analysis of 91 studies exploring the epidemiology of vancomycin intermediate-resistant S.aureus (VISA) strains during 1997 and 2014, reported higher VISA incidence rates in Asia, including MENA, compared to other regions [26]. Given that suboptimal antimicrobial therapy of MRSA contributes to the emergence of resistant strains [27], these findings highlight the potentially high prevalence of inadequate vancomycin treatment in MENA. This can be attributed to non-adherence to clinical practice guidelines or the limited generalizability of vancomycin $\mathrm{AUC}_{24} /$ MIC targets reported elsewhere. Genetic and epidemiologic diversity between MRSA clones across various geographical regions and time-points have been reported worldwide, including MENA [12-18]. However, the currently applied vancomycin dosing nomograms in the MENA region are based on published Western vancomycin pharmacokinetic-pharmacodynamic targets, due to the lack of studies reporting MENA-specific targets. Expatriates from different MENA and Asian countries constitute the majority of Qatar's population, with nationals reported to be $<15 \%$ $[28,29]$. Therefore, we aimed to explore MENA-specific pharmacokinetic-pharmacodynamic vancomycin targets to understand the reasons for vancomycin treatment failures in the MENA region.

Although the 2009 consensus guidelines recommend trough-only monitoring [3], to the best of our knowledge, no prospective randomized controlled trials (RCTs) have been conducted to compare the clinical and pharmacokinetic outcomes between the traditional peak-trough-based and the trough-only-based vancomycin TDM approaches. Additionally, the vancomycin $\mathrm{AUC}_{24} / \mathrm{MIC}$ cure breakpoint in MENA-specific populations and bacterial strains has not yet been studied. Therefore, this prospective parallel-group pragmatic multicenter RCT was conducted to compare the clinical and pharmacokinetic outcomes of peak-troughbased and trough-only-based vancomycin TDM approaches and to evaluate the relationship between vancomycin AUC ${ }_{24} / \mathrm{MIC}$ ratios and cure in the MENA population. 


\section{Methods}

\subsection{Study Design and Setting}

A multicenter pragmatic two parallel-group RCT was conducted in three tertiary care hospitals under Hamad Medical Corporation (HMC) in Qatar-Al-Wakrah Hospital (AWH), Al-Khor Hospital (AKH), and Hamad General Hospital (HGH).

\subsection{Study Population and Sample Size Calculation}

Inclusion criteria included hospitalized adults ( $\geq 18$ years) with suspected/confirmed staphylococcal or other Grampositive infection requiring treatment with vancomycin for at least 3 days based on the attending physician's judgment. Exclusion criteria included renal instability [abrupt absolute increase in serum creatinine $(\mathrm{SCr}) \geq 0.5 \mathrm{mg} / \mathrm{dL}$ from baseline or a percentage increase in $\mathrm{SCr} \geq 50 \%$ within $48 \mathrm{~h}$ ]; end-stage renal disease; transplant; immunosuppression; active malignancy; receiving antineoplastic agents; HIV or absolute neutrophil counts $<1000$ cells $/ \mathrm{mm}^{3}$; vancomycin allergy; history of recurrent resistant peritonitis; administration of $<4$ doses of vancomycin or for $<72 \mathrm{~h}$; vancomycin administration for post-surgical infection prophylaxis; pregnancy; subjects not able to undergo blood sampling per clinician judgment; anuria (urine output $<100 \mathrm{~mL} /$ day); symptomatic anemia; and hemoglobin $<8 \mathrm{~g} / \mathrm{dL}$.

Sample size was calculated a priori to be 120 subjects (60 subjects per arm) [30]. The primary endpoint used for sample size calculation was clinical effectiveness (therapeutic cure). Based on the meta-analysis of Ye et al., we assumed $85 \%$ cure rates in the peak-trough-based vancomycin TDM arm versus $60 \%$ cure rates in the control arm [31]. An attrition rate of $20 \%$, a significance level of $5 \%$, and a power of $80 \%$ were considered in the a priori power analysis [30]. Given the unexpectedly slow recruitment rate, interim analysis was conducted at 7 months. Statistically significant differences in the primary study outcome of clinical effectiveness were achieved. Thus, the study was ended after the enrollment of 65 subjects since a significant difference was detected in the primary study outcome.

\subsection{Randomization and Blinding}

Participants who provided informed consent and fulfilled the eligibility criteria were randomly assigned to one of the two study groups-(1) peak-trough (intervention) group or (2) trough-only (control) group. An allocation ratio of 1:1 was applied using a computer-generated list of random numbers. Due to the pragmatic nature of this trial, blinding was not possible since the treating clinical team needed to apply the dose change recommendations after justification. Thus, the method used for dose adjustment was revealed as part of justification, when requested by the attending physician.

\subsection{Study Interventions}

All subjects were initiated on vancomycin initial/empiric doses by the attending physician prior to enrollment in the study [3, 32-35]. Initiation or discontinuation of vancomycin treatment was the sole decision of the treating primary team and was not influenced by the study investigators. This trial was pragmatic in nature; thus, subjects were treated as part of routine care. No co-medications, medical procedures, dietary restrictions or restrictions to participation in other concurrent research were applied.

In the two study arms, target $C_{\text {trough,ss }}$ was as per the recommendations of the HMC institutional guidelines and the clinical practice guidelines: $>10 \mathrm{mg} / \mathrm{L}$ for less serious infections such as skin and soft tissue infections (SSTIs); and $15-20 \mathrm{mg} / \mathrm{L}$ for complicated infections such as bacteremia, infective endocarditis, osteomyelitis, meningitis, hospitalacquired pneumonia, and serious SSTI (e.g., necrotizing fasciitis) caused by $S$. aureus [3]. Creatinine clearance $\left(\mathrm{CL}_{\mathrm{CR}}\right)$ was calculated using the Cockcroft-Gault equation [36]. In patients with declined renal function or at risk of nephrotoxicity, the lower end $C_{\text {trough,ss }}$ targets were used. In the intervention arm, target $C_{\text {max,ss }}$ was $20-40 \mathrm{mg} / \mathrm{L}$ [1], stratified according to the patient's renal function. In patients with normal $\mathrm{CL}_{\mathrm{CR}}, C_{\max , \mathrm{ss}} \geq 30-35 \mathrm{mg} / \mathrm{L}$ was targeted. Otherwise, a lower $C_{\text {max.ss }}$ was used, considering clinical judgment and dosing feasibility. This range was used with the objective of sufficient infected tissue penetration while preventing adverse drug reactions (ADRs), by accounting for possible declined renal function and other nephrotoxicity risk factors [1].

\subsubsection{Blood Specimen Collection for Initial Vancomycin Concentrations}

In both study arms, five initial vancomycin blood samples were collected through venipuncture. Routine vancomycin trough concentrations were collected $30 \mathrm{~min}$ before the fourth dose $\left(C_{\text {trough,ss } 1}\right)$. For the study purpose, four vancomycin blood samples (10 $\mathrm{mL}$ of blood for each) were obtained at $1-2 \mathrm{~h}$ post fourth dose infusion $\left(C_{\mathrm{max}, \mathrm{ss}}\right), 30 \mathrm{~min}$ before the fifth dose $\left(C_{\text {trough,ss } 2}\right)$, and two concentrations in between the peak and trough concentrations $\left(\mathrm{C}_{1}, \mathrm{C}_{2}\right)$ after the fourth dose (i.e., at steady state). For instance, if the patient was receiving a 12-hourly vancomycin regimen, $\mathrm{C}_{1}$ and $\mathrm{C}_{2}$ were drawn at $4 \mathrm{~h}$ and $8 \mathrm{~h}$ post fourth dose infusion. On the other hand, if the patient was taking an 8-hourly regimen, $\mathrm{C}_{1}$ and $\mathrm{C}_{2}$ were drawn at $4 \mathrm{~h}$ and $6 \mathrm{~h}$ post fourth dose infusion. 


\subsubsection{Biochemistry and Microbiology Specimen Analysis}

Vancomycin blood specimens were collected and analyzed at HMC biochemistry laboratories using particle-enhanced turbidimetric inhibition immunoassay (PETINA) [37]. Specimens from $\mathrm{HGH}$ and $\mathrm{AKH}$ were analyzed using the Architect c16000 (Abbott, USA) analyzer [38], while specimens from AWH were analyzed using the UniCel ${ }^{\circledR}$ DxC 600 (Beckman Coulter, USA) analyzer [39]. To determine vancomycin susceptibilities, microbiology cultures were processed using the broth microdilution test technique (BD Phoenix AP, USA) $[40,41]$. Our institution uses the vancomycin MRSA susceptibly breakpoint $(\leq 2 \mathrm{mg} / \mathrm{L}$ ) set out by the Clinical and Laboratory Standards Institute (CLSI). For definitive sensitive cultures, the institutional laboratories reported MICs as ' $<1 \mathrm{mg} / \mathrm{L}$ ' or ' $=1 \mathrm{mg} / \mathrm{L}$ '. A survey of institutional vancomycin MIC of sensitive MRSA isolates collected between April 2015 and January 2016 showed that the MICs for most cultures were reported as $1 \mathrm{mg} / \mathrm{L}$. Thus, we assumed an MIC of $1 \mathrm{mg} / \mathrm{L}$ for all specimens in this study.

\subsubsection{Trough-Only-Based Vancomycin Dosing Adjustment}

In the control arm, only trough concentrations were considered for dosing adjustments. If the target trough was not achieved, a new dose or a new dosing interval was calculated using trough-only linear method equations (Eqs. 1, 2 ) as below [1, 42, 43], where $C_{\text {trough,ss }}$ is the target new steady-state trough concentration; $C_{\mathrm{t}}$ is the current trough concentration; $D_{\text {old }}$ is the old dose that resulted in $C_{\mathrm{t}} ; \tau_{\text {old }}$ is the old dosing interval that resulted in $C_{\mathrm{t}}$; and $\tau_{\text {new }}$ is the new dosing interval. Either the 'dose-only change' or the 'dosing interval-only' change equation was used based on clinical feasibility and practicality.

Dose-only change:

New dose $=\left(C_{\text {trough,ss }} / C_{\mathrm{t}}\right) D_{\text {old }}$

Dosing interval-only change:

New dosing interval $\left(\tau_{\text {new })}=\left(C_{\mathrm{t}} / C_{\text {trough,ss }}\right) \tau_{\text {old }}\right.$

\subsubsection{Peak-Trough-Based Vancomycin Dosing Adjustment}

Based on both the peak and trough vancomycin concentrations, a patient's individualized pharmacokinetic parameters were calculated and used in dose adjustment calculations. If either the peak or trough or both concentrations were nontherapeutic, a new vancomycin dosing regimen was calculated and administered. Intravenous (IV) bolus equations (Eqs. 3-7) were used provided that the vancomycin infusion time was short relative to the patient-specific vancomycin half-life $[1,42]$. If this assumption was not valid due to augmented renal clearance (ARC) or infusion durations $>1 \mathrm{~h}$, IV intermittent infusion equations (Eqs. 8-13) were used as below [1,42]; where $K_{\mathrm{e}}$ is the elimination rate constant; $k_{0}$ is the infusion rate; $t_{1 / 2}$ is the half-life; $V$ is the volume of distribution; $\mathrm{Cl}$ is the clearance; $D$ is the dose; $\mathrm{C}_{1}$ is the vancomycin concentration at time $t_{1} ; \mathrm{C}_{2}$ is the vancomycin concentration at time $t_{2} ; C_{\mathrm{p}}$ is the peak concentration; $\mathrm{C}_{\mathrm{t}}$ is the trough concentration; $C_{\text {max,ss }}$ is the target steady-state peak concentration; $C_{\text {trough,ss }}$ is the target steady-state trough concentration; $\tau$ is the dosing interval; and $t^{\prime}$ is the infusion duration.

IV bolus infusion equations:

$K_{\mathrm{e}}=-\left(\ln C_{1}-\ln C_{2}\right) /\left(t_{1}-t_{2}\right)$

$t_{1 / 2}=\ln 2 / K_{\mathrm{e}}$

$V=D / C_{\mathrm{p}}-C_{\mathrm{t}}$

$\tau=\left(\ln C_{\text {max,ss }}-\ln C_{\text {trough,ss }}\right) / k_{\mathrm{e}}$

Dose $=C_{\mathrm{max}, \mathrm{ss}} V\left(1-e^{-\mathrm{ke} \tau}\right)$

IV intermittent infusion equations:

$K_{\mathrm{e}}=-\left(\ln C_{1}-\ln C_{2}\right) /\left(t_{1}-t_{2}\right)$

$t_{1 / 2}=\ln 2 / K_{\mathrm{e}}$

$V=\left[k_{0}\left(1-e^{-\mathrm{ket} \prime}\right)\right] /\left\{k_{\mathrm{e}}\left[C_{\mathrm{p}}-\left(C_{\mathrm{t}} e^{-\mathrm{ket} \prime}\right)\right]\right\}$

$\mathrm{Cl}=K_{\mathrm{e}} V$

$\tau=\left(\ln C_{\text {max,ss- }} \ln C_{\text {trough,ss }}\right) / k_{\mathrm{e}}+t^{\prime}$

Dose $=C_{\text {max }, \text { ss }} K_{\mathrm{e}} V\left[\left(1-e^{-\mathrm{ke} \tau}\right) /\left(1-e^{-\mathrm{ket} t}\right)\right]$

\subsubsection{Post-Dose Adjustment Vancomycin Monitoring}

After any dose adjustment, the time to new steady state was calculated and post-dose adjustment peak and trough vancomycin concentrations were measured. If measured vancomycin concentrations were not at target levels, additional dose adjustments were applied as discussed above. Otherwise, vancomycin peak and trough concentration monitoring continued every $24-48 \mathrm{~h}$.

\subsection{Study Endpoints}

\subsubsection{Primary Outcome Measures}

The primary outcome measures of clinical effectiveness were (1) vancomycin $\mathrm{AUC}_{24}$ /MIC cure breakpoint; (2) 
therapeutic cure (composite endpoint); and (3) therapeutic failure (composite endpoint). Therapeutic cure was defined as clinical cure and/or microbiologic cure [6, 44-46]. Clinical cure was defined as the absence of infection signs/symptoms without the need for additional antibiotic treatment. Microbiologic cure was defined as negative blood cultures at 5 days after vancomycin treatment initiation. Therapeutic failure included at least one of the following [6, 44-46]clinical failure, microbiologic failure, premature discontinuation due to ADR or all-cause mortality. Clinical failure was defined as insufficient clinical response to initial vancomycin therapy necessitating antibiotic change. Microbiological failure was defined as a positive culture at $\geq 5$ days after initiation of vancomycin treatment. Neutropenia was defined as absolute neutrophil counts $<1000 / \mu \mathrm{L}[47,48]$. Nephrotoxicity was defined as 'a minimum of two or three consecutive $\mathrm{SCr}$ increases (defined as an increase of $0.5 \mathrm{mg} / \mathrm{dL}$ or at least $50 \%$ increase from baseline) after several days of vancomycin therapy' [3]. All-cause mortality was defined as death from any cause during enrollment in the trial.

\subsubsection{Secondary Outcome Measures}

Secondary outcomes included (1) length of hospital stay (LOS); (2) number of dose adjustments required; (3) cumulative vancomycin doses received; and (4) duration of vancomycin treatment.

\subsection{Statistical Analysis}

Intention-to-treat analysis was applied. Descriptive and inferential statistics were conducted (SPSSv.23; IBM ${ }^{\circledR}$, Armonk, NY, USA) to compare the differences in clinical outcomes between the intervention (i.e., peak-trough-based vancomycin TDM approach) and the control (i.e., troughonly-based vancomycin TDM approach) arms. Skewness test was applied to ensure normality of data (choice of parametric vs nonparametric tests). For comparison between the groups, Student's $t$-test, Mann-Whitney $U$-test or chisquared test was used as appropriate. All comparisons were carried out using an a priori significance level of 0.05 (two-sided tests). AUCs were calculated using the nonlinear mixed-effects population pharmacokinetics modeling approach (NONMEM v.7.3, ICON, USA) [49]. Classification and regression tree (CART) analysis was conducted using SPSS v. 23 (IBM ${ }^{\circledR}$; Armonk). AUC ${ }_{24} / \mathrm{MIC}$, vancomycin cumulative doses, treatment duration, infected physiologic compartment, ethnicity, $\mathrm{CL}_{\mathrm{CR}}$ and TDM approach were tested against clinical effectiveness. To assess the predictive accuracy of the generated models, misclassification risk estimates with standard error were used [50].

\section{Results}

\subsection{Baseline Characteristics of the Study Participants}

Sixty-five subjects were enrolled (35 in the trough-onlybased vancomycin TDM group and 30 in the peak-troughbased vancomycin TDM group). Baseline characteristics were similar between the study groups and are summarized in Table 1. Central nervous system infections $(n=15$, $23.1 \%)$, lower respiratory tract infections $(n=16,24.6 \%)$ and sepsis or septic shock $(n=11,16.9 \%)$ were the most frequently occurring infections. Vancomycin was initiated as a definitive treatment in more than half of the cases $(n=35$, $53.3 \%)$. Of the identified bacteria $(n=35)$, MRSA $(n=17$, $48.6 \%)$, MSSA ( $n=8,22.9 \%)$, S. epidermidis $(n=5,14.3 \%)$ and Enterococcus faecium $(n=4,11.4 \%)$ constituted the most frequent positive microbiologic cultures. Approximately half of the study participants were critically ill and hospitalized in critical care units $(n=31,47.7 \%)$. Physicianprescribed initial vancomycin dosing regimens were comparable between the study groups.

\subsection{Clinical Outcomes of Peak-Trough-Based Versus Trough-Only-Based Vancomycin TDM Approaches}

Peak-trough-based vancomycin TDM was significantly associated with higher infection cure rates compared to trough-only-based vancomycin TDM $[p$ value $=0.02$; Table 2]. Compared to the control group (trough-only-based TDM group), the intervention group (peak-trough-based TDM group) required non-statistically significant shorter duration of vancomycin treatment and hospitalization by 0.5 days and 4.5 days, respectively [ $p$ value $>0.05$; Table 2] No statistically significant differences were observed for other safety endpoints between the two monitored groups [ $p$ value $>0.05$; Table 2].

\subsection{Clinical Pharmacokinetic Outcomes of Peak- Trough-Based Versus Trough-Only-Based Vancomycin TDM Approaches}

Initial peak and trough vancomycin serum concentrations were not therapeutic in $30.2 \%(n=19)$ and $80 \%(n=52)$ of cases, respectively (Table 3 ). Individual vancomycin clinical pharmacokinetic parameters were comparable between the study groups (Table 3 ). Patients enrolled in the peak-trough-based group received TDM earlier than the trough-only-based group by 0.5 days $[p$ value $=0.001]$. Vancomycin dosing requirements significantly differed between the two vancomycin TDM approaches; compared 
Table 1 Baseline characteristics of the study participants

\begin{tabular}{|c|c|c|}
\hline Variable & $\begin{array}{l}\text { Trough-monitoring } \\
\text { group } \\
(n=35)\end{array}$ & $\begin{array}{l}\text { Peak-trough- } \\
\text { monitoring } \\
\text { group } \\
(n=30)\end{array}$ \\
\hline Age (years), mean \pm SD & $41.7 \pm 19.56$ & $42.4 \pm 14.47$ \\
\hline BMI $\left(\mathrm{kg} / \mathrm{m}^{2}\right)$, median [IQR] & $26.7[5.2]$ & $25.4[7.8]$ \\
\hline ABW (kg), median [IQR] & $73.1[23.6]$ & $70[19.3]$ \\
\hline Height $(\mathrm{cm})$, median [IQR] & $169[13]$ & $168[10.5]$ \\
\hline \multicolumn{3}{|l|}{ Gender, $n(\%)$} \\
\hline Male & $30(85.7)$ & $22(73.3)$ \\
\hline Female & $5(14.3)$ & $8(26.7)$ \\
\hline \multicolumn{3}{|l|}{ Ethnicity, $n(\%)$} \\
\hline MENA & $23(65.7)$ & $8(26.7)$ \\
\hline Asian (non-MENA) & $11(31.4)$ & $20(66.7)$ \\
\hline African (non-MENA) & $1(2.9)$ & $2(6.7)$ \\
\hline \multicolumn{3}{|l|}{ Hospitalization ward, $n(\%)$} \\
\hline Intensive care units ${ }^{\mathrm{a}}$ & $13(37.1)$ & $18(60)$ \\
\hline Burns unit & $2(5.7)$ & $0(0)$ \\
\hline Medical ward & $11(31.4)$ & $9(30)$ \\
\hline Surgical/orthopedic ward & $9(25.7)$ & $3(10)$ \\
\hline \multicolumn{3}{|l|}{ Diagnosis, $n(\%)$} \\
\hline CNS infection ${ }^{\mathrm{b}}$ & $5(15.3)$ & $10(33.3)$ \\
\hline Bacteremia & $4(11.4)$ & $2(6.7)$ \\
\hline Skin and soft tissue infection & $4(11.4)$ & $4(13.3)$ \\
\hline Bone and joint infection & $6(17.1)$ & $2(6.7)$ \\
\hline Sepsis/septic shock & $5(14.3)$ & $6(20)$ \\
\hline Lower respiratory tract infection & $7(20)$ & $5(16.7)$ \\
\hline Infective endocarditis & $1(2.9)$ & $0(0)$ \\
\hline Intra-abdominal infection & $3(8.6)$ & $1(3.3)$ \\
\hline \multicolumn{3}{|l|}{ Infected physiologic compartment, $n(\%)$} \\
\hline CNS compartment ${ }^{\mathrm{b}}$ & $5(14.3)$ & $10(33.3)$ \\
\hline Blood compartment ${ }^{\mathrm{c}}$ & $13(37.1)$ & $9(30)$ \\
\hline Lung compartment & $7(20)$ & $5(16.7)$ \\
\hline Other tissues ${ }^{\mathrm{d}}$ & $10(28.6)$ & $6(20)$ \\
\hline \multicolumn{3}{|l|}{ Vancomycin treatment type, $n(\%)$} \\
\hline Empiric & $16(45.7)$ & $14(46.7)$ \\
\hline Definitive & $19(54.3)$ & $16(53.3)$ \\
\hline \multicolumn{3}{|l|}{ Positive microbiologic cultures, $n(\%)$} \\
\hline MRSA & $8(42.1)$ & $9(56.3)$ \\
\hline MSSA & $5(26.3)$ & $3(18.6)$ \\
\hline S. epidermidis & $4(21.1)$ & $1(6.3)$ \\
\hline S. constellatus & $1(5.3)$ & $0(0)$ \\
\hline E. faecium & $1(5.3)$ & $3(18.8)$ \\
\hline \multicolumn{3}{|l|}{ Pre-enrollment vancomycin treatment details } \\
\hline Pre-enrollment days on vancomycin treatment, median [IQR] & $2[0.5]$ & $1.5[1]$ \\
\hline Dose (mg/dose), median [1QR] & $1000[0]$ & $1000[0]$ \\
\hline Dose (mg/kg/dose), median [IQR] & $14.3[5.6]$ & $14.6[3.7]$ \\
\hline Total daily dose (mg/day), median [IQR] & $2000[1000]$ & 2000 [125] \\
\hline Total daily dose (mg/kg/day), median [IQR] & $28.6[16.5]$ & $29.2[7.4]$ \\
\hline Cumulative doses received (mg), median [IQR] & $4000[1250]$ & $5000[2063]$ \\
\hline Cumulative doses received $(\mathrm{mg} / \mathrm{kg})$, median [IQR] & $59.4[25.04]$ & $66.8[29.6]$ \\
\hline
\end{tabular}


Table 1 (continued)

Table 2 Clinical outcomes of peak-trough-based versus trough-only-based vancomycin therapeutic drug monitoring approaches

\begin{tabular}{|c|c|c|}
\hline Variable & $\begin{array}{l}\text { Trough-monitoring } \\
\text { group } \\
(n=35)\end{array}$ & $\begin{array}{l}\text { Peak-trough- } \\
\text { monitoring } \\
\text { group } \\
(n=30)\end{array}$ \\
\hline \multicolumn{3}{|l|}{ Laboratory parameters } \\
\hline White blood cells $\left(\times 10^{9} \mathrm{IU} / \mathrm{L}\right)$, mean $\pm \mathrm{SD}$ & $13.36 \pm 7.9$ & $12.8 \pm 6.02$ \\
\hline Hemoglobin (g/dL), median [IQR] & $11.53[2.32]$ & $11.7[4.15]$ \\
\hline Neutrophils $\left(\times 10^{9} \mathrm{IU} / \mathrm{L}\right)$, median [IQR] & $8[9.8]$ & $8.2[7.7]$ \\
\hline $\mathrm{SCr}(\mu \mathrm{mol} / \mathrm{L})$, median $[\mathrm{IQR}]$ & $65[36]$ & $67[30]$ \\
\hline Concomitant antibiotics, $n(\%)$ & $18(51.4)$ & $22(55)$ \\
\hline Beta-lactams & $9(25.7)$ & $9(30)$ \\
\hline Carbapenems & $10(15.4)$ & $11(16.9)$ \\
\hline Cephalosporins & $9(25.7)$ & $12(40)$ \\
\hline Clindamycin & $2(5.7)$ & $1(3.3)$ \\
\hline Linezolid & $0(0)$ & $4(13.3)$ \\
\hline Rifampicin & $1(2.9)$ & $1(3.3)$ \\
\hline Concomitant nephrotoxic agents, $n(\%)$ & $12(34.3)$ & $12(40)$ \\
\hline Amphotericin B & $0(0)$ & $2(6.7)$ \\
\hline NSAIDs & $8(22.9)$ & $10(33.3)$ \\
\hline ACEI/ARBs & $4(11.1)$ & $1(3.3)$ \\
\hline Loop/thiazide diuretics & $4(11.4)$ & $6(20)$ \\
\hline Acyclovir & $1(2.9)$ & $0(0)$ \\
\hline \multicolumn{3}{|l|}{ Comorbidities, $n(\%)$} \\
\hline Diabetes mellitus & $6(17.1)$ & $8(26.7)$ \\
\hline Chronic kidney disease & $1(2.9)$ & $2(6.7)$ \\
\hline Hypertension & $7(20)$ & $11(36.7)$ \\
\hline Coronary vascular disease & $2(5.7)$ & $4(13.3)$ \\
\hline Heart failure & $1(2.9)$ & $2(6.7)$ \\
\hline
\end{tabular}

$B M I$ body mass index, $A B W$ actual body weight, MENA Middle East and North Africa, MRSA methicillinresistant $S$. aureus, MSSA methicillin-sensitive $S$. aureus

${ }^{a}$ Includes trauma, medical and surgical intensive care units

${ }^{\mathrm{b}}$ Involves meningitis, encephalitis and ventriculitis

${ }^{\mathrm{c}}$ Includes blood, intra-abdominal and cardiac infections

${ }^{\mathrm{d}}$ Includes skin, soft tissue, bone and joint infections

\begin{tabular}{llll}
\hline Variable & $\begin{array}{l}\text { Trough-only-mon- } \\
\text { itoring group } \\
(n=35)\end{array}$ & $\begin{array}{l}\text { Peak-trough- } \\
\text { monitoring group } \\
(n=30)\end{array}$ & $p$ value $^{\mathrm{a}}$ \\
\hline $\begin{array}{l}\text { Vancomycin treatment efficacy outcomes, } n(\%) \\
\text { Therapeutic cure }\end{array}$ & $17(48.6)$ & $23(76.7)$ & 0.020 \\
$\quad$ Therapeutic failure & $18(51.4)$ & $7(23.3)$ & \\
Vancomycin treatment safety outcomes, $n(\%)$ & $3(8.6)$ & $1(3.3)$ & 0.381 \\
Neutropenia & $1(2.9)$ & $1(3.3)$ & 0.912 \\
Nephrotoxicity & $3(8.6)$ & $2(6.7)$ & 0.774 \\
All-cause mortality, $n(\%)$ & $20[6-117]$ & $15.5[4-68.9]$ & 0.320 \\
Length of hospitalization (days), median [min-max] & $7[1-28]$ & $6.5[1-32]$ & 0.319 \\
Total duration on vancomycin treatment (days), median \\
$\quad$ min-max]
\end{tabular}

${ }^{a}$ Chi-squared test or Mann-Whitney $U$-test 
to the trough-only-based vancomycin TDM group, the peak-trough-based group required lower average vancomycin single doses and total daily doses by $370 \mathrm{mg} / \mathrm{dose}$ and $927 \mathrm{mg} /$ day, respectively [ $p$ value $<0.05$; Table 3; Fig. 1]. Despite the similar duration on vancomycin treatment between the study groups, the trough-only-based vancomycin TDM recipients received clinically significant higher median cumulative vancomycin doses by $6,522 \mathrm{mg}$ [ $p$ value $>0.05$; Table 3]. Patients who received troughonly-based vancomycin TDM required more dose adjustments to achieve target serum concentrations compared to the intervention group [ $p$ value $>0.05$; Table 3]. Furthermore, the trough-only-based monitoring was associated with recommended vancomycin dosing regimens of relatively low dosing frequencies and large single doses, necessitating longer infusion durations that exceeded $1 \mathrm{~h}$ (Table 3 ). The compared TDM approaches resulted in statistically and clinically significant different peak concentrations; peak-trough-based vancomycin dose adjustments compared to trough-only based vancomycin dose adjustments resulted in achievement of target peaks for $94.1 \%$ versus $69 \%$ of the time, respectively $[p$ value $=0.006$; Table 3$]$. Interestingly, peak-trough-based vancomycin doses resulted in similar rates of therapeutic troughs and AUCs compared to troughonly-based vancomycin doses (Table 3 ).

\subsection{Association Between Vancomycin $\mathrm{AUC}_{24} / \mathrm{MIC}$ and Cure}

CART identified $\mathrm{CL}_{\mathrm{CR}}<7.85 \mathrm{~L} / \mathrm{h}, \mathrm{AUC}_{24 /} \mathrm{MIC}$, and the type of vancomycin TDM approach as significant determinants of therapeutic outcomes with 100, 58.4 and $45.8 \%$ normalized importance to the model, respectively. Maintaining AUC ${ }_{24} / \mathrm{MIC}$ between 565 and 1256 has been associated with cure. All subjects who achieved an $\mathrm{AUC}_{24} / \mathrm{MIC} \leq 1256$ and received peak-trough-based vancomycin TDM achieved clinical success rates $[100 \%, n=19]$. Maintenance of AUC ${ }_{24} / \mathrm{MIC}>565$ was identified to be correlated with cure in trough-only-based TDM recipients [84.6\%, $n=11]$. No minimum $\mathrm{AUC}_{24} / \mathrm{MIC}$ breakpoint was detected by CART in the peak-trough-based group. The predictive performance was high $(88.6 \%)$ with low misclassification risks (11.4\%), suggesting robustness.

\section{Discussion}

To our knowledge, this is the first pragmatic head-to-head RCT that (1) prospectively compared two routinely used vancomycin TDM approaches; (2) reported MENA-specific $\mathrm{AUC}_{24} / \mathrm{MIC}$ targets; and (3) identified a maximum $\mathrm{AUC}_{24} /$ MIC threshold for clinical benefit. Studies have suggested that vancomycin TDM was associated with higher clinical success rates and less nephrotoxicity compared to non-TDM groups $[31,51]$. To date, studies in this area compared vancomycin TDM recipients with non-TDM recipients, and were mostly based on observational research designs [31]. In addition, no studies reported MENA-specific $\mathrm{AUC}_{24} / \mathrm{MIC}$ targets. The present pragmatic RCT aimed to address these questions.

Despite similar $\mathrm{AUC}_{24}$ exposures, peak-trough-based TDM was associated with higher cure rates compared to trough-only-based TDM. This unexpected finding can be interpreted in two ways. First, it questions whether $\mathrm{AUC}_{24} /$ MIC is the optimal vancomycin pharmacokinetic-pharmacodynamic target. Fukumori's group reported the area under the trough level as a novel pharmacokinetic-pharmacodynamic parameter that more strongly correlates with vancomycin clinical efficacy compared to $\mathrm{AUC}_{24}$ [52]. Second, it suggests that cure may be more associated with the extent of consistency, sustainability and fluctuations of vancomycin exposure during the course of therapy, rather than a total single exposure estimate. This notion serves as the basis for studies advocating the administration of vancomycin as continuous infusion, rather than intermittent infusion [53-55]. Compared to intermittent infusion, continuous infusion resulted in more consistent and sustained exposure at the infection site, despite similar AUCs [54]. Furthermore, continuous infusion achieved target concentrations faster and was associated with less serum fluctuations [55]. Collectively these studies align with the finding that a minimum cure breakpoint $\left(\mathrm{AUC}_{24} / \mathrm{MIC}>565\right)$ was only detected in the trough-only TDM arm, while peak-trough-based vancomycin dosing was not associated with a minimum threshold. This suggests that peak-trough-based vancomycin dosing, using the specified peak/trough targets, is associated with more sustained and consistent vancomycin exposure that resulted in achieving the minimum $\mathrm{AUC}_{24} / \mathrm{MIC}$ threshold for cure at most times, unlike trough-only based dosing. Vancomycin continuous infusion is not feasible for all clinical settings or patient situations. For example, a patient may be on other vancomycin-incompatible intravenous therapy. Indeed, the peak-trough-based approach may serve as a more practical alternative to continuous infusion that needs to be explored in future studies.

Maintaining $\mathrm{AUC}_{24} / \mathrm{MIC}$ between 565 and 1256 has been associated with cure. This breakpoint is higher than the minimum $\mathrm{AUC}_{24} / \mathrm{MIC}$ cure breakpoints that ranged from 398 to 451 in seven observational cohort studies [19]. Additionally, this work is the first to identify a maximum $\mathrm{AUC}_{24} / \mathrm{MIC}$ cure threshold that, if exceeded, no extra clinical benefit is likely as long as the $\mathrm{CL}_{\mathrm{CR}}$ is $<130 \mathrm{~mL} / \mathrm{min}$. This concurs with the emerging concept of $\mathrm{ARC}\left(\mathrm{CL}_{\mathrm{CR}}>120-150 \mathrm{~mL} / \mathrm{min}\right)$, that is associated with decreased vancomycin exposure and negative clinical outcomes [56-60]. Although studies reported that targeting, higher $\mathrm{AUC}_{24} / \mathrm{MIC}$ ratios was associated 
Table 3 Clinical pharmacokinetic outcomes associated with peak-trough-based versus trough-only-based vancomycin therapeutic drug monitoring approaches

\begin{tabular}{|c|c|c|c|}
\hline Variable & $\begin{array}{l}\text { Trough-only-monitoring group } \\
(n=35)\end{array}$ & $\begin{array}{l}\text { Peak-trough-moni- } \\
\text { toring group } \\
(n=30)\end{array}$ & $p$ value $^{\mathrm{a}}$ \\
\hline \multicolumn{4}{|l|}{ Pharmacokinetic parameters at treatment initiation } \\
\hline$V_{\mathrm{d}}(\mathrm{L})$, mean $\pm \mathrm{SD}$ & $48.5 \pm 10.7$ & $51.14 \pm 9.96$ & 0.311 \\
\hline$K_{\mathrm{e}}\left(\mathrm{h}^{-1}\right)$, mean $\pm \mathrm{SD}$ & $0.094 \pm 0.05$ & $0.089 \pm 0.051$ & 0.702 \\
\hline $\mathrm{Cl}(\mathrm{L} / \mathrm{h})$, mean $\pm \mathrm{SD}$ & $4.15 \pm 2.22$ & $4.24 \pm 2.20$ & 0.861 \\
\hline$t_{1 / 2}(\mathrm{~h})$, median $[\mathrm{IQR}]$ & $8.01[11.12]$ & $7.23[9.75]$ & 0.722 \\
\hline $\mathrm{CrCl}(\mathrm{L} / \mathrm{h})$, median $[\mathrm{IQR}]$ & $6.51[3.44]$ & $6.45[3.12]$ & 0.374 \\
\hline AUC per initial ${ }^{\mathrm{b}}$ dose $\left(\mathrm{mg}{ }^{*} \mathrm{~h} / \mathrm{L}\right)$, median [IQR] & $227[195.6]$ & $228[273.01]$ & 0.590 \\
\hline \multicolumn{4}{|l|}{ 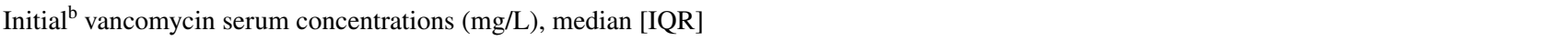 } \\
\hline Trough-1 & $9[8.3]$ & $8.4[12.9]$ & 0.732 \\
\hline Peak & $25[10]$ & $27.9[17.8]$ & 0.863 \\
\hline Random-1 & $18.9[9.4]$ & $18[18.1]$ & 0.837 \\
\hline Random-2 & $11.9[8.7]$ & $11.1[13.28]$ & 0.638 \\
\hline Trough-2 & $10.6[10.5]$ & $8.9[15.1]$ & 0.844 \\
\hline \multicolumn{4}{|l|}{ Interpretation of initial ${ }^{\mathrm{b}}$ peak vancomycin concentrations, $n(\%)^{\mathrm{d}}$} \\
\hline Therapeutic & $27(77.1)$ & $17(60.7)$ & 0.158 \\
\hline Non-therapeutic & $8(22.9)$ & $11(39.3)$ & \\
\hline \multicolumn{4}{|l|}{ Interpretation of initial ${ }^{\mathrm{b}}$ vancomycin trough concentrations, $n(\%)$} \\
\hline Therapeutic & $6(17.1)$ & $7(23.3)$ & 0.534 \\
\hline Non-therapeutic & $29(82.9)$ & $23(76.7)$ & \\
\hline $\begin{array}{l}\text { Minimum number of dose adjustments required to first therapeutic } \\
\text { serum concentrations, median [min-max] }\end{array}$ & $2[1-5]$ & $1[1-3]$ & 0.105 \\
\hline \multicolumn{4}{|l|}{ Overall vancomycin dosing requirements } \\
\hline Single dose $(\mathrm{mg} /$ dose $)$, mean $\pm \mathrm{SD}$ & $1385.71 \pm 530.62$ & $1015 \pm 332.221$ & 0.001 \\
\hline Single dose $(\mathrm{mg} / \mathrm{kg} / \mathrm{dose})$, mean $\pm \mathrm{SD}$ & $19.03 \pm 7.76$ & $14.09 \pm 5.68$ & 0.005 \\
\hline Total daily dose (mg/day), mean \pm SD & $3834.49 \pm 1,362.83$ & $2907 \pm 1,416.08$ & 0.009 \\
\hline Total daily dose $(\mathrm{mg} / \mathrm{kg} /$ day $)$, mean $\pm \mathrm{SD}$ & $52.83 \pm 21.59$ & $40.78 \pm 21.25$ & 0.027 \\
\hline Cumulative doses received $(\mathrm{mg})$, mean $\pm \mathrm{SD}$ & $26,275 \pm 24,190$ & $19,753 \pm 21,893$ & 0.192 \\
\hline \multicolumn{4}{|l|}{ Vancomycin dosing interval, $n(\%)$} \\
\hline Q6 h & $6(17.1)$ & $11(36.7)$ & 0.091 \\
\hline Q8 h & $16(45.7)$ & $12(40)$ & \\
\hline Q12 h & $13(37.1)$ & $4(13.4)$ & \\
\hline Q18 h & $0(0)$ & $1(3.3)$ & \\
\hline Q24 h & $0(0)$ & $1(3.3)$ & \\
\hline Q36 h & $0(0)$ & $1(3.3)$ & \\
\hline \multicolumn{4}{|l|}{ Vancomycin infusion duration, $n(\%)$} \\
\hline Infused over $0.5 \mathrm{~h}$ & $1(2.9)$ & $0(0)$ & 0.297 \\
\hline Infused over $1 \mathrm{~h}$ & $19(54.3)$ & $22(73.3)$ & \\
\hline Infused over $1.5 \mathrm{~h}$ & $10(28.5)$ & $8(26.7)$ & \\
\hline Infused over $2.5 \mathrm{~h}$ & $2(5.7)$ & $0(0)$ & \\
\hline Infused over $3 \mathrm{~h}$ & $2(5.7)$ & $0(0)$ & \\
\hline Infused over $4 \mathrm{~h}$ & $1(2.9)$ & $0(0)$ & \\
\hline AUC per TDM adjusted dose $(\mathrm{mg} * \mathrm{~h} / \mathrm{L})$, median [IQR] & $270[156.02]$ & $223[168.82]$ & 0.590 \\
\hline $\mathrm{AUC}_{24} / \mathrm{MIC}$, median $[\mathrm{IQR}]$ & $772[412.95]$ & 708 [260.87] & 0.762 \\
\hline Post-dose adjustment peak concentration $(\mathrm{mg} / \mathrm{L})$, mean \pm SD & $35.94 \pm 7.7$ & $30.38 \pm 5.17$ & 0.021 \\
\hline Post-dose adjustment trough concentration $(\mathrm{mg} / \mathrm{L})$, mean $\pm \mathrm{SD}$ & $16.8 \pm 3.09$ & $15.6 \pm 3.49$ & 0.596 \\
\hline
\end{tabular}


Table 3 (continued)

\begin{tabular}{lll}
\hline Variable & $\begin{array}{c}\text { Trough-only-monitoring group } \\
(n=35)\end{array}$ & $\begin{array}{l}\text { Peak-trough-moni- } \\
\text { toring group } \\
(n=30)\end{array}$ \\
\hline $\begin{array}{l}\text { Interpretation of post-dose adjustment }{ }^{\mathrm{c}} \text { peak concentrations, } n(\%)^{\mathrm{d}} \\
\text { Therapeutic }\end{array}$ & $29(69)$ & $32(94.1)$ \\
Subtherapeutic & $13(31)$ & $2(5.9)$ \\
Interpretation of post-dose adjustment ${ }^{\mathrm{c}}$ trough concentrations, $n(\%)$ & $25(44.6)$ & $20(54.1)$ \\
$\quad$ Therapeutic & $19(33.9)$ & $10(27)$ \\
Subtherapeutic & $12(21.4)$ & $7(18.9)$ \\
Supratherapeutic & & 0.606 \\
\hline
\end{tabular}

${ }^{\text {a }}$ Chi-squared test, Mann-Whitney $U$-test or Student's $t$-test

${ }^{\mathrm{b}}$ Initial represents pre-TDM doses and concentrations

${ }^{c} 56$ dose adjustments were applied in the trough-only arm while 37 dose adjustments were applied in the peak-trough arm

${ }^{\mathrm{d}}$ Missing values

Fig. 1 Vancomycin dosing requirements of peak-troughbased versus trough-only-based vancomycin therapeutic drug monitoring recipients
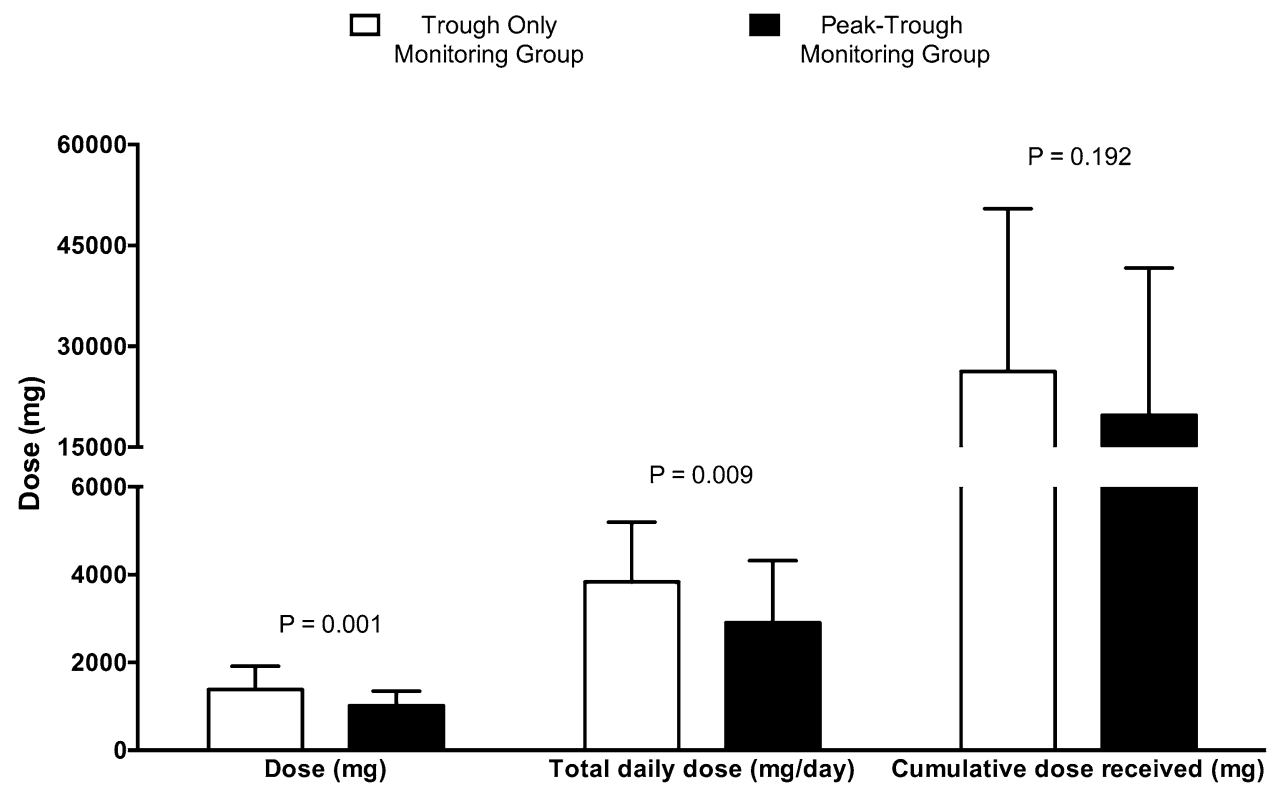

with better clinical outcomes $[19,61]$, the question regarding a maximum $\mathrm{AUC}_{24} / \mathrm{MIC}$ for clinical benefit remained unanswered in the current literature. It should be carefully noted that pharmacokinetic-pharmacodynamic targets (i.e., $\mathrm{AUC}_{24} / \mathrm{MIC}$ ) serve only for clinical efficacy outcomes while absolute vancomycin exposure measures should be monitored for safety $[1,3,62,63]$.

Emerging evidence suggests the promising clinical usefulness of the peak-trough-based vancomycin TDM approach [22, 64, 65], and questions the clinical benefit of trough-only-based vancomycin dosing [61, 66, 67]. Consistent with other studies, this RCT suggests that peak-troughbased vancomycin dosing may be associated with lower vancomycin exposure, LOS and dose adjustments, which needs to be confirmed in larger scale trials. Finch et al. reported that 2-concentration-based AUC-guided vancomycin dosing resulted in less vancomycin exposure, total daily doses and nephrotoxicity versus trough-only-guided dosing [22]. Similar clinical benefits of vancomycin peak concentration monitoring have been suggested elsewhere [64, 65]. Peak-trough-based TDM allowed significantly better attainment of therapeutic vancomycin concentrations [64]. It has been reported that vancomycin-related ADRs (i.e., nephrotoxicity and neutropenia) may be related to exposure [23, 47, 48, 68-72], with trough concentrations $>15 \mathrm{mg} / \mathrm{L}$ having a significantly higher risk [69]. According to a meta-analysis of 17 observational studies, vancomycin dosing that targeted higher trough concentrations $(>15 \mathrm{mg} / \mathrm{L})$ was associated with significantly more nephrotoxicity and no significant improvement in mortality or cure rates [66]. In deep-seated 
MRSA, trough concentrations $>15 \mathrm{mg} / \mathrm{L}$ did not result in shorter LOS, lower mortality rates, or higher treatment success rates versus trough concentrations $<15 \mathrm{mg} / \mathrm{L}$ [67]. In fact, vancomycin trough concentrations $>15 \mathrm{mg} / \mathrm{L}$ were associated with a higher incidence of nephrotoxicity [67]. A meta-analysis of 14 observational studies showed that vancomycin dosing based on trough concentration targets $(15-20 \mathrm{mg} / \mathrm{L})$ was not associated with better clinical outcomes in mortality, bacteremia persistence and treatment failure [61]. Therefore, peak-trough-based vancomycin dosing provides a potential strategy to decrease vancomycin exposure, which will reflect into lower medication utilization, less vancomycin-related ADRs, and decreased emergence of vancomycin-resistant strains. Furthermore, the possibly lower LOS with peak-trough-based dosing would potentially result in a lower incidence of nosocomial infections. Thus, this approach provides a potential strategy to maximize clinical outcomes with vancomycin treatment, as well as decrease the economic burden on healthcare systems.

This study has several strengths. First, the present RCT is of a pragmatic nature. The key feature of pragmatic designs is the ability to assess the effectiveness of an intervention in routine situations to maximize the external validity of the study findings [73]. Due to the limited generalizability of exploratory RCTs to routine clinical practice, the concept of pragmatism has emerged during the past decades [73-75]. Exploratory RCTs are conducted under ideal circumstances in which an intervention is more likely to work, which is not how real-life situations are in clinical settings; thus, they possess limited generalizability and may fail in many routine clinical situations [73]. Therefore, it has been reported that the plethora of exploratory RCTs are of limited use to healthcare policymakers and clinicians [75]. Due to the pragmatic nature of this study, the researchers did not intervene on indication appropriateness and initial dosing of vancomycin; suspected or confirmed Gram-positive infections requiring vancomycin treatment were included, with no restrictions to MRSA like other AUC studies. The study setting included multiple centers and wards in order to be reflective of the variabilities in clinical practice. An important observation is the lack of initial vancomycin target attainment with physician-initiated dosing at most times, which may be due to deviations from the guideline-recommended empiric doses in our clinical setting. The reasons for such non-compliance need to be explored in future audits. In addition, no restrictions on infection type, critical illness state, pharmacotherapeutic or mechanical co-interventions were applied. Thus, the implications of the study findings are of clinical relevance, as it tested effectiveness rather than efficacy alone. Second, the prospective nature of the study allowed accurate vancomycin dosing and blood specimen collection. The accuracy of sampling times and dosing assures the internal validity of clinical pharmacokinetic studies. Unlike most clinical evaluations that estimated the AUC based on estimated renal clearance, which does not accurately predict vancomycin clearance [23], the present work used actual individualized vancomycin clearance to estimate the AUC. Together, these aspects suggest high internal validity of the study, with considerable generalizability.

The present findings need to be interpreted with caution due to some important limitations. This RCT was of limited sample size and was unblinded. The exact MICs were not available for all subjects since many received vancomycin as empiric therapy. For subjects with confirmed sensitive cultures, HMC laboratories reported MIC as $1 \mathrm{mg} / \mathrm{L}$ at all instances with values of $<1 \mathrm{mg} / \mathrm{L}$ rounded to $1 \mathrm{mg} / \mathrm{L}$. Future larger scale double-blinded pragmatic RCTs are needed to confirm these findings.

\section{Conclusion}

In conclusion, this is the first head-to-head pragmatic RCT that compared peak-trough-based versus trough-only-based vancomycin TDM approaches. Compared to trough-onlybased vancomycin TDM, peak-trough-based vancomycin TDM strategy was associated with higher cure rates and less vancomycin doses. Furthermore, maintaining an AUC ${ }_{24} / \mathrm{MIC}$ between 565 and 1256 was associated with cure. Future larger scale trials are warranted to confirm these study findings.

\section{Ethical Considerations}

Informed consent was obtained from all participants included in the study. All procedures performed were in accordance with the 1964 Helsinki declaration and its later amendments and national institutional research committees. This study was approved by HMC Medical Research Center and Qatar University Institutional Review Board as well as the research committees of AWH, AKH and HGH.

Acknowledgements Open Access funding provided by the Qatar National Library. We would like to thank Dr. Hani Abdelaziz and Dr. Eman El-Mekaty for their efforts and contributions in the design and implementation of this study. We would also like to thank all staff at HMC who helped to conduct the study.

\section{Compliance with Ethical Standards}

Funding This study was funded by Qatar University Internal Research Grant (QUST-CPH-SPR-14/15-12).

Conflicts of interest All authors declare no conflict of interest. 
Open Access This article is distributed under the terms of the Creative Commons Attribution-NonCommercial 4.0 International License (http://creativecommons.org/licenses/by-nc/4.0/), which permits any noncommercial use, distribution, and reproduction in any medium, provided you give appropriate credit to the original author(s) and the source, provide a link to the Creative Commons license, and indicate if changes were made.

\section{References}

1. Bauer LA. Applied clinical pharmacokinetics. 3rd ed. USA: McGraw Hill; 2014

2. Neely MN, Youn G, Jones B, Jelliffe RW, Drusano GL, Rodvold KA, et al. Are vancomycin trough concentrations adequate for optimal dosing? Antimicrob Agents Chemother. 2014;58(1):309-16.

3. Rybak M, Lomaestro B, Rotschafer JC, Moellering R Jr, Craig W, Billeter M, et al. Therapeutic monitoring of vancomycin in adult patients: a consensus review of the American Society of HealthSystem Pharmacists, the Infectious Diseases Society of America, and the Society of Infectious Diseases Pharmacists. Am J Health Syst Pharm. 2009;66(1):82-98.

4. Moise-Broder PA, Forrest A, Birmingham MC, Schentag JJ. Pharmacodynamics of vancomycin and other antimicrobials in patients with staphylococcus aureus lower respiratory tract infections. Clin Pharmacokinet. 2004;43(13):925-42.

5. Gawronski KM, Goff DA, Brown J, Khadem TM, Bauer KA. A stewardship program's retrospective evaluation of vancomycin AUC24/MIC and time to microbiological clearance in patients with methicillin-resistant staphylococcus aureus bacteremia and osteomyelitis. Clin Ther. 2013;35(6):772-9.

6. Brown J, Brown K, Forrest A. Vancomycin AUC24/MIC ratio in patients with complicated bacteremia and infective endocarditis due to methicillin-resistant staphylococcus aureus and its association with attributable mortality during hospitalization. Antimicrob Agents Chemother. 2012;56(2):634-8.

7. Holmes NE, Turnidge JD, Munckhof WJ, Robinson JO, Korman TM, O'Sullivan MV, et al. Vancomycin AUC/MIC ratio and 30-day mortality in patients with staphylococcus aureus bacteremia. Antimicrob Agents Chemother. 2013;57(4):1654-63.

8. Lee HY, Chen CL, Liu SY, Yan YS, Chang CJ, Chiu CH. Impact of molecular epidemiology and reduced susceptibility to glycopeptides and daptomycin on outcomes of patients with methicillin-resistant staphylococcus aureus bacteremia. PLoS One. 2015;10(8): 0136171 .

9. Torun MM, Bahar H, Demirci M, Altas K, Bagdatli Y, Kocazeybek B, et al. Two heterogeneously vancomycin-intermediate clinical isolates of methicillin-sensitive and methicillin-resistant staphylococcus aureus in a Turkish university hospital: brief report of a surveillance study. Int J Antimicrob Agents. 2005;26(6):508-10.

10. Moise PA, Sakoulas G, Forrest A, Schentag JJ. Vancomycin in vitro bactericidal activity and its relationship to efficacy in clearance of methicillin-resistant staphylococcus aureus bacteremia. Antimicrob Agents Chemother. 2007;51(7):2582-6.

11. Robinson JO, Pearson JC, Christiansen KJ, Coombs GW, Murray RJ. Community-associated versus healthcare-associated methicillin-resistant staphylococcus aureus bacteraemia: a 10-year retrospective review. Eur J Clin Microbiol Infect Dis. 2009;28(4):353-61.

12. Deurenberg RH, Stobberingh EE. The evolution of staphylococcus aureus. Infect Genet Evol. 2008;8(6):747-63.

13. Goudarzi M, Bahramian M, Satarzadeh Tabrizi M, Udo EE, Figueiredo AM, Fazeli M, et al. Genetic diversity of methicillin resistant staphylococcus aureus strains isolated from burn patients in Iran: sT239-SCCmec III/t037 emerges as the major clone. Microb Pathog. 2017;105:1-7.

14. Goudarzi M, Seyedjavadi SS, Nasiri MJ, Goudarzi H, Sajadi Nia R, Dabiri H. Molecular characteristics of methicillin-resistant staphylococcus aureus (MRSA) strains isolated from patients with bacteremia based on MLST, SCCmec, spa, and agr locus types analysis. Microb Pathog. 2017;104:328-35.

15. Boswihi SS, Udo EE. Methicillin-resistant staphylococcus aureus: an update on the epidemiology, treatment options and infection control. Curr Med Res Pract. 2018;8(1):18-24.

16. Tokajian S. New epidemiology of staphylococcus aureus infections in the Middle East. Clin Microbiol Infect. 2014;20(7):624-8.

17. Chen CJ, Huang YC. New epidemiology of Staphylococcus aureus infection in Asia. Clin Microbiol Infect. 2014;20(7):605-23.

18. Changchien $\mathrm{CH}$, Chen YY, Chen SW, Chen WL, Tsay JG, Chu C. Retrospective study of necrotizing fasciitis and characterization of its associated methicillin-resistant staphylococcus aureus in Taiwan. BMC Infect Dis. 2011;11:297.

19. Men PLH, Zhai S, Zhao R. Association between the AUC0-24/ MIC ratio of vancomycin and its clinical effectiveness: a systematic review and meta-analysis. PLoS One. 2016;11(1):e0146224.

20. Drennan PG, Begg EJ, Gardiner SJ, Kirkpatrick CMJ, Chambers ST. The dosing and monitoring of vancomycin - what is the best way forward? Int J Antimicrob Agents. 2018.

21. Neely MN, Kato L, Youn G, Kraler L, Bayard D, van Guilder M, et al. Prospective trial on the use of trough concentration versus area under the curve to determine therapeutic vancomycin dosing. Antimicrob Agents Chemother. 2018;62(2):e02042-17.

22. Finch NA, Zasowski EJ, Murray KP, Mynatt RP, Zhao JJ, Yost $\mathrm{R}$, et al. A quasi-experiment to study the impact of vancomycin area under the concentration-time curve-guided dosing on vancomycin-associated nephrotoxicity. Antimicrob Agents Chemother. 2017;61(12):e01293-17.

23. Pai MP, Neely M, Rodvold KA, Lodise TP. Innovative approaches to optimizing the delivery of vancomycin in individual patients. Adv Drug Deliv Rev. 2014;77:50-7.

24. Patel N, Pai MP, Rodvold KA, Lomaestro B, Drusano GL, Lodise TP. Vancomycin: we can't get there from here. Clin Infect Dis. 2011;52(8):969-74

25. Mogle BT, Steele JM, Seabury RW, Dang UJ, Kufel WD. Implementation of a two-point pharmacokinetic AUC-based vancomycin therapeutic drug monitoring approach in patients with methicillin-resistant staphylococcus aureus bacteraemia. Int $\mathbf{J}$ Antimicrob Agents. 2018;52(6):805-10.

26. Zhang S, Sun X, Chang W, Dai Y, Ma X. Systematic review and meta-analysis of the epidemiology of vancomycin-intermediate and heterogeneous vancomycin-intermediate staphylococcus aureus isolates. PLoS One. 2015;10(8):e0136082.

27. Rahimipour F, Ghazvini K, Youssefi M. Reports of vancomycinresistant staphylococcus aureus from Middle East countries. Arch Clin Infect Dis. 2018;13(2):e59522.

28. Qatar population. 2018 [Accessed 24 Feb 2019]. http://worldpopul ationreview.com/countries/qatar-population/.

29. Quarterly bulletin for population and social statistics. Qatar Ministry of Development and Planning Statistics. 2018 [Accessed 24 Feb 2019]. https://www.mdps.gov.qa/en/statistics1/Pages/Lates tStats/20170320.aspx.

30. Kane SP. Sample size calculator. ClinCalc: http://clincalc.com/ Stats/SampleSize.aspx Updated July 1, 2017 [Accessed 7 October 2015]. http://clincalc.com/Stats/SampleSize.aspx.

31. Ye ZK, Tang HL, Zhai SD. Benefits of therapeutic drug monitoring of vancomycin: a systematic review and meta-analysis. PLoS One. 2013;8(10):e77169.

32. Stevens DL, Bisno AL, Chambers HF, Dellinger EP, Goldstein EJ, Gorbach SL, et al. Practice guidelines for the diagnosis and management of skin and soft tissue infections: 2014 update by 
the Infectious Diseases Society of America. Clin Infect Dis. 2014;59(2): $10-52$.

33. Mermel LA, Allon M, Bouza E, Craven DE, Flynn P, O'Grady $\mathrm{NP}$, et al. Clinical practice guidelines for the diagnosis and management of intravascular catheter-related infection: 2009 update by the Infectious Diseases Society of America. Clin Infect Dis. 2009;49(1):1-45.

34. Tunkel AR, Hartman BJ, Kaplan SL, Kaufman BA, Roos KL, Scheld WM, et al. Practice guidelines for the management of bacterial meningitis. Clin Infect Dis. 2004;39(9):1267-84.

35. Liu C, Bayer A, Cosgrove SE, Daum RS, Fridkin SK, Gorwitz RJ, et al. Clinical practice guidelines by the Infectious Diseases Society of America for the treatment of methicillin-resistant staphylococcus aureus infections in adults and children: executive summary. Clin Infect Dis. 2011;52(3):285-92.

36. Creatinine clearance estimate by Cockcroft-Gault equation. [Accessed 7 October 2015] https://reference.medscape.com/calcu lator/creatinine-clearance-cockcroft-gault.

37. Arneson W, Brickell J. Clinical chemistry: a laboratory perspective. Philadelphia: F. A. Davis Company; 2007.

38. Architect c16000 USA: Abbott Laboratories 2007. [Accessed 7 October 2015]. http://www.nearmedic.ru/upload/files/ Doc_429_207.pdf.

39. Synchron systems chemistry information sheet: vancomycin [Package Insert]. Brea, CA:Beckman Coulter, Inc; 2015. [Accessed 3 June 2017]. https://www.beckmancoulter.com/wsrpo rtal/techdocs?docname=/cis/A18566/AN/EN_VANC.pdf.

40. Laboratory procedure: BD Pheonix automated microbiology systems [Package insert]. USA: BD Phoenix AP. [Accessed 3 June 2017]. http://legacy.bd.com/ds/technicalCenter/clsi/clsi-Phoen ix_GramPositive_V5.15_V4.31.pdf.

41. Wiegand I, Hilpert K, Hancock RE. Agar and broth dilution methods to determine the minimal inhibitory concentration (MIC) of antimicrobial substances. Nat Protoc. 2008;3(2):163-75.

42. Shargel L, W-Pong S, Yu A. Applied biopharmaceutics and pharmacokinetics. 6th ed. USA: McGraw-Hill Companies; 2012.

43. Bauer LA. Evaluation of a simplified method to adjust vancomycin trough concentrations. Pharmacotherapy. 2005;25(10):1503.

44. Walraven CJ, North MS, Marr-Lyon L, Deming P, Sakoulas G, Mercier RC. Site of infection rather than vancomycin MIC predicts vancomycin treatment failure in methicillin-resistant staphylococcus aureus bacteraemia. J Antimicrob Chemother. 2011;66(10):2386-92.

45. Clemens EC, Chan JD, Lynch JB, Dellit TH. Relationships between vancomycin minimum inhibitory concentration, dosing strategies, and outcomes in methicillin-resistant staphylococcus aureus bacteremia. Diagn Microbiol Infect Dis. 2011;71(4):408-14.

46. Castillo JS, Leal AL, Cortes JA, Alvarez CA, Sanchez R, Buitrago $\mathrm{G}$, et al. Mortality among critically ill patients with methicillinresistant staphylococcus aureus bacteremia: a multicenter cohort study in Colombia. Rev Panam Salud Publica. 2012;32(5):343-50.

47. Pai MP, Mercier RC, Koster SA. Epidemiology of vancomycininduced neutropenia in patients receiving home intravenous infusion therapy. Ann Pharmacother. 2006;40(2):224-8.

48. Morris A, Ward C. High incidence of vancomycin-associated leucopenia and neutropenia in a cardiothoracic surgical unit. J Infect. 1991;22(3):217-23.

49. Bonate P. Pharmacokinetic-pharmacodynamic modeling and simulation. 2nd ed. USA: Springer; 2014.

50. Sutton CD. Classification and regression trees bagging and boosting. Handbook of statistics. 24. ebook: Elsevier; 2005.

51. Welty TE, Copa AK. Impact of vancomycin therapeutic drug monitoring on patient care. Ann Pharmacother. 1994;28(12):1335-9.

52. Fukumori S, Tsuji Y, Mizoguchi A, Kasai H, Ishibashi T, Iwamura $\mathrm{N}$, et al. Association of the clinical efficacy of vancomycin with the novel pharmacokinetic parameter area under the trough level (AUTL) in elderly patients with hospital-acquired pneumonia. J Clin Pharm Ther. 2016;41(4):399-402.

53. Waineo MF, Kuhn TC, Brown DL. The pharmacokinetic/pharmacodynamic rationale for administering vancomycin via continuous infusion. J Clin Pharm Ther. 2015;40(3):259-65.

54. Byl B, Jacobs F, Wallemacq P, Rossi C, de Francquen P, Cappello $M$, et al. Vancomycin penetration of uninfected pleural fluid exudate after continuous or intermittent infusion. Antimicrob Agents Chemother. 2003;47(6):2015-7.

55. Vuagnat A, Stern R, Lotthe A, Schuhmacher H, Duong M, Hoffmeyer P, et al. High dose vancomycin for osteomyelitis: continuous vs. intermittent infusion. J Clin Pharm Ther. 2004;29(4):351-7.

56. Hobbs AL, Shea KM, Roberts KM, Daley MJ. Implications of augmented renal clearance on drug dosing in critically ill patients: a focus on antibiotics. Pharmacotherapy. 2015;35(11):1063-75.

57. Udy AA, Baptista JP, Lim NL, Joynt GM, Jarrett P, Wockner L, et al. Augmented renal clearance in the ICU: results of a multicenter observational study of renal function in critically ill patients with normal plasma creatinine concentrations. Crit Care Med. 2014;42(3):520-7.

58. Fuster-Lluch O, Geronimo-Pardo M, Peyro-Garcia R, Lizan-Garcia M. Glomerular hyperfiltration and albuminuria in critically ill patients. Anaesth Intensive Care. 2008;36(5):674-80.

59. Claus BO, Hoste EA, Colpaert K, Robays H, Decruyenaere J, De Waele JJ. Augmented renal clearance is a common finding with worse clinical outcome in critically ill patients receiving antimicrobial therapy. J Crit Care. 2013;28(5):695-700.

60. Baptista JP, Sousa E, Martins PJ, Pimentel JM. Augmented renal clearance in septic patients and implications for vancomycin optimisation. Int J Antimicrob Agents. 2012;39(5):420-3.

61. Prybylski JP. Vancomycin trough concentration as a predictor of clinical outcomes in patients with staphylococcus aureus bacteremia: a meta-analysis of observational studies. Pharmacotherapy. 2015;35(10):889-98.

62. Chavada R, Ghosh N, Sandaradura I, Maley M, Van Hal SJ. Establishment of an AUC0-24 threshold for nephrotoxicity is a step towards individualized vancomycin dosing for methicillinresistant staphylococcus aureus bacteremia. Antimicrob Agents Chemother. 2017;61(5):e02535-16.

63. Zasowski EJ, Murray KP, Trinh TD, Finch NA, Pogue JM, Mynatt $\mathrm{RP}$, et al. Identification of vancomycin exposure-toxicity thresholds in hospitalized patients receiving intravenous vancomycin. Antimicrob Agents Chemother. 2018;62(1):e01684-17.

64. Hong J, Krop LC, Johns T, Pai MP. Individualized vancomycin dosing in obese patients: a two-sample measurement approach improves target attainment. Pharmacotherapy. 2015;35(5):455-63.

65. Iwamoto T, Kagawa Y, Kojima M. Clinical efficacy of therapeutic drug monitoring in patients receiving vancomycin. Biol Pharm Bull. 2003;26(6):876-9.

66. Meng L, Fang Y, Chen Y, Zhu H, Long R. High versus low vancomycin serum trough regimen for gram-positive infections: a meta-analysis. J Chemother. 2015;27(4):213-20.

67. Hermsen ED, Hanson M, Sankaranarayanan J, Stoner JA, Florescu MC, Rupp ME. Clinical outcomes and nephrotoxicity associated with vancomycin trough concentrations during treatment of deepseated infections. Expert Opin Drug Saf. 2010;9(1):9-14.

68. Lodise TP, Lomaestro B, Graves J, Drusano GL. Larger vancomycin doses (at least four grams per day) are associated with an increased incidence of nephrotoxicity. Antimicrob Agents Chemother. 2008;52(4):1330-6.

69. van Hal SJ, Paterson DL, Lodise TP. Systematic review and meta-analysis of vancomycin-induced nephrotoxicity associated with dosing schedules that maintain troughs between 15 
and 20 milligrams per liter. Antimicrob Agents Chemother. 2013;57(2):734-44.

70. Black E, Lau TT, Ensom MH. Vancomycin-induced neutropenia: is it dose- or duration-related? Ann Pharmacother. 2011;45(5):629-38.

71. Elyasi S, Khalili H, Dashti-Khavidaki S, Mohammadpour A. Vancomycin-induced nephrotoxicity: mechanism, incidence, risk factors and special populations. A literature review. Eur J Clin Pharmacol. 2012;68(9):1243-55.
72. Segarra-Newnham M, Tagoff SS. Probable vancomycin-induced neutropenia. Ann Pharmacother. 2004;38(11):1855-9.

73. Patsopoulos NA. A pragmatic view on pragmatic trials. Dialogues Clin Neurosci. 2011;13(2):217-24.

74. Williams HC, Burden-Teh E, Nunn AJ. What is a pragmatic clinical trial? J Invest Dermatol. 2015;135(6):1-3.

75. Zwarenstein $\mathrm{M}, \mathrm{Oxman} \mathrm{A}$. Why are so few randomized trials useful, and what can we do about it? J Clin Epidemiol. 2006;59(11):1125-6. 